\title{
NGHIÊN CÚU NÂNG CAO TÍNH AN TOÀN CON NGƯÒ̀I TRONG Ô TÔ KHÁCH XẢY RA VA CHẠM TRỰC DIỆN
}

\author{
NGUYẼ̃N THÀNH TÂM \\ Khoa Công nghệ Động lưc, Trường Đại học Công nghiệp thành phố Hồ Chí Minh; \\ nguyenthanhtam@iuh.edu.vn
}

Tóm tắt. Nghiên cứu tổn thương hành khách là khâu quan trọng của quá trình thiết kế ô tô. Dựa vào tiêu chuẩn an toàn Châu Âu ECE R94, ứng dụng phần mềm MADYMO và HYPERMESH tiến hành xây dựng mô hình và mô phỏng phân tích tổn thương con người trong xe khách xảy ra va chạm trực diện. Kết quả mô phỏng cho thấy, gia tốc va chạm cao làm cho hành khách bị tổn thương phần đầu, cồ rất nghiêm trọng. Nguyên nhân chủ yếu là do các hệ thống an toàn không được đảm bảo, kết cấu đầu xe hấp thụ năng lượng thấp. Trên cơ sở kết quả phân tích cơ chế tổn thương hành khách, tiến hành cải tiến hệ thống an toàn, kết cấu hấp thụ năng lượng va chạm. Kết quả cải tiến cho thấy, các giá trị tổn thương của hành khách đã thỏa mãn yêu cầu của tiêu chuẩn Châu Âu ECE R94.

Từ khóa. va chạm trực diện, hấp thụ năng lượng, phân tích mô phỏng, tổn thương, tiêu chuẩn ECE R94

\section{STUDY ON HUMAN SAFETY IMPROVEMENT IN BUS FRONTAL COLLISION}

\begin{abstract}
It is important to study the passenger injury in vehicle design. Based on ECE R94 standard, the bus safety simulation model was established and human injury was analysed in bus frontal crash was analyed by MADYMO and HYPERMESH software. The simulation results showed that the crash acceleration of bus very high, the passenger's head and neck were seriously injured. The main reasons were the safety system was not assured and energy absorption of bus head structure was very low. Based on the analysis results of injury mechanisms of passengers, the safety system and energy absorption structure of bus were improved. Improvement results showed that, the injury values of the passengers arcording to the requirements of European Standard ECE R94.
\end{abstract}

Key words. frontal impact, energy absorption, simulation analysis, injury, ECE R94 Standard

\section{LÒ̀I NÓI ĐẦU}

Cùng với phát triển kinh tế xã hội của đất nước, mạng lưới giao thông công cộng ngày càng được phát triển, số lượng phương tiện giao thông đường bộ tăng trưởng không ngừng từng năm. Cùng với đó là những vụ tai nạn giao thông nghiêm trọng làm thiệt hại nghiêm trọng về con người và kinh tế, theo Ưy ban an toàn giao thông quốc gia thì trong 9 tháng đầu năm 2015 đã có hơn 16.189 vụ tai nạn giao thông, làm chết 6.305 người và làm bị thương 14.929 người [1]. Trong đó các vụ có tính chất đặc biệt nghiêm trọng liên quan tới xe khách ghế ngồi, đặc biệt là các vụ tai nạn va chạm trực diện làm nhiều người thương vong.

Do đó, việc phân tích tổn thương của hành khách khi xe khách ghế ngồi xảy ra va chạm trực trở thành điểm nóng nghiên cứu. Tác giả Muhammand Aamir Hasan đã nghiên cứu phân tích so sánh sự biến dạng kết cấu và thiệt hại về người ngồi trong xe khi xảy ra va chạm trực diện vào mặt tường và cây cột, tuy nhiên không đề xuất hoặc cải tiến nhằm giảm tổn thương con người [2]. Tác giả Nguyễn Thành Tâm đã nghiên cứu thiết kế tối ưu hóa kết cấu khung xương và sát - xi ô tô khách, nhưng chưa có nghiên cứu tổn thương hành khách khi xe xảy ra va chạm [3]. Tác giả Zhang Weigang nghiên cứu thiết kế cải tiến khung xương và sát - xi xe khách khi xảy ra va chạm trực diện bằng cách thiết kế bộ hấp thu năng lượng loại ông thép, cho thấy sự va đập, gia tốc và ứng suất lớn dễ phá vỡ kết cấu sát - xi xe khách [4]. Nghiên cứu này sử dụng phần mềm HYPERMESH và MADYMO để xây dựng mô hình xe khách ghế ngồi, mô phỏng phân tích và cải tiến kết cấu khung đầu xe nhằm đảm bảo không gian an toàn cho tài xế và hành khách theo tiêu chuẩn ECE R66. Sau đó mô phỏng phân tích tổn thương con người ngồi trong xe khách va chạm trực diện $100 \%$ diện tích đầu xe. Kết quả mô phỏng cho thấy, hành khách bị tổn thương nghiêm 
trọng khi các hệ thống an toàn không được đảm bảo, gia tốc va chạm cao. Trên cơ sở kết quả phân tích cơ chế tổn thương hành khách, tiến hành cải tiến hệ thống an toàn, cơ cấu hấp thụ năng lượng. Kết quả cải tiến cho thấy, các giá trị tổn thương của hành khách đã thỏa mãn yêu cầu của tiêu chuẩn Châu Âu ECE R94.

\section{XÂY DỰNG MÔ HÌNH PHÂN TÍCH TÍNH TỔN THƯƠNG}

Dựa vào mô hình CAD 3D ô tô khách từ nhà sản xuất, sử dụng phần mềm HYPERMESH trong môi trường LS - DYNA để chia lưới cho mô hình (dạng lưới vuông $20 \mathrm{~mm}$ ), gắn khối lượng cho các bộ phận như thùng nhiên liệu, ắc quy, hệ thống điều hòa không khí, cửa kính, động cơ,... Sau đó tiến hành chọn vật liệu, thiết lập thuộc tính vật liệu. Kết cấu khung xương sử dụng sắt Q235, kết cấu sát - xi sử dụng sắt Q345, thuộc tính vật liệu như ở bảng 1 [3].

Bảng 1: Thuộc tính vật liệu

\begin{tabular}{|l|l|l|l|l|}
\hline \multicolumn{1}{|c|}{ Tên } & $\begin{array}{c}\text { Môdun đàn hồi } \\
(\mathrm{GPa})\end{array}$ & \multicolumn{1}{|c|}{ Hệ số Poisson } & \multicolumn{1}{c|}{$\begin{array}{c}\text { Khối lượng riêng } \\
\left(\mathrm{kg} / \mathrm{mm}^{3}\right)\end{array}$} & $\begin{array}{c}\text { Úng suất giới } \\
\text { hạn }(\mathrm{MPa})\end{array}$ \\
\hline Q345 & 210 & 0,3 & $7,85.10^{-6}$ & 345 \\
\hline Q235 & 210 & 0,3 & $7,85.10^{-6}$ & 235 \\
\hline
\end{tabular}

Khi đã thiết lập được các thông số trên, tiến hành xuất tọa độ trọng tâm, khối lượng và moment quán tính cho từng thành phần khung xe để làm dữ liệu đầu vào cho MADYMO. Từ các dữ liệu thu được, xây dựng được mô hình đa vật thể cứng khung xe và mô hình phần tử hữu hạn đầu xe trong MADYMO. Các điều kiện biên được thiết lập theo tiêu chuẩn ECE R94 (vận tốc khi xảy ra va chạm là $56 \mathrm{~km} / \mathrm{h}$, gia tốc trọng trường là $\mathrm{g}=9,81 \mathrm{~m} / \mathrm{s}^{2}$. Tường va chạm, mặt đất và khung xe sử dụng các SURFACE.ELLIPSOID và SURFACE.PLANE, phần đầu xe là phần tử hữu hạn FE.MODEL, trong đó tọa độ element (phần tử) và các node (nút) trong TABLE được xuất từ HYPERMESH, độ dày của phần sát - xi ban đầu là $8 \mathrm{~mm}$, khung đầu xe là $2 \mathrm{~mm}$. Nhằm trực quan phân tích biến dạng xe, thiết lập không gian an toàn cho xe theo tiêu chuẩn ECE R66. Để phân tích tổn thương con người, thiết lập người nộm Hybrid III $50^{\text {th }}$ và các hệ thống an toàn (dây đai, túi khí cho hành khách và người lái) vào mô hình. Mô hình xe khách ghế ngồi đa thể cứng với đầu xe là phần tử hữu hạn sau khi xây dựng như ở hình 1 và vị trí khảo sát tổn thương hành khách và người lái ở hình 2.

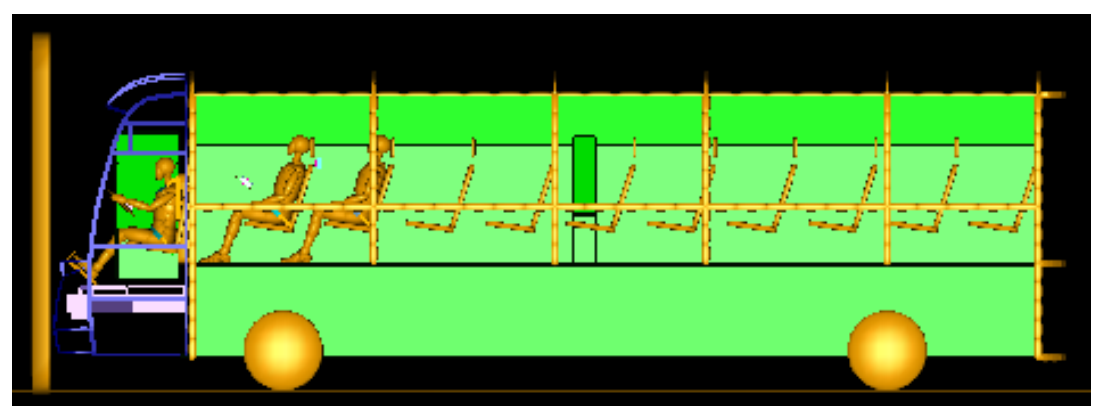

Hình 1: Mô hình mô phỏng phân tích tổn thương con người

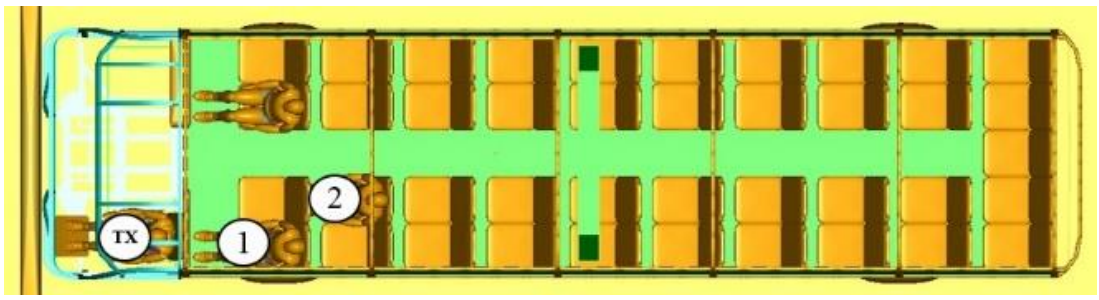

Hình 2: Vị trí khảo sát hành khách và tài xế 


\section{PHÂN TÍCH KÊTT QUẢ MÔ PHỎNG}

Để mô phỏng phân tích một cách toàn diện quá trình va chạm và tổn thương hành khách và tài xế khi xe xảy ra va chạm trực diện, nghiên cứu này ứng dụng tiêu chuẩn đánh giá tổn thương Châu Âu ECE R94 và tiến hành mô phỏng phân tích cho 03 trường hợp (Trường hợp 1 là không trang bị dây đai, túi khí; Trường hợp 2 là hành khách trang bị dây đai 2 điểm, người lái 3 điểm; Trường hợp 3 là hành khách trang bị dây đai 3 điểm, người lái 3 điểm và túi khí).

\subsection{Không trang bị dây đai, túi khí (Trường hơp 1)}

Dùng phần mềm MADYMO mô phỏng phân tích tổn thương của hành khách khi xe xảy ra va chạm trực diện, thời gian mô phỏng là $200 \mathrm{~ms}$, tốc độ va chạm là $56 \mathrm{~km} / \mathrm{h}$. Hình mô phỏng quá trình va chạm được xuất bởi phần mềm HYPERVIEW, hình 3 thể hiện xe va chạm tại thời điểm $93 \mathrm{~ms}$.

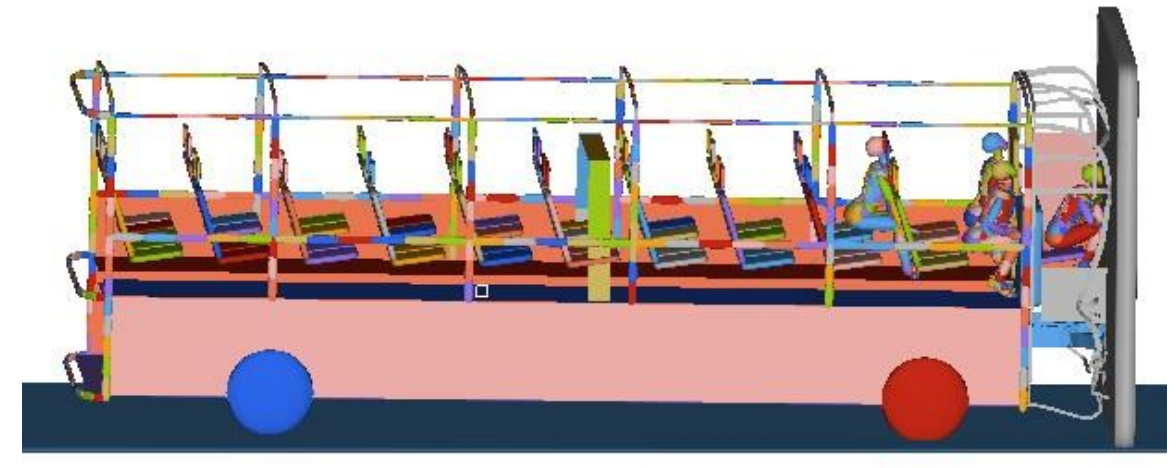

Hình 3: Hành khách và người lái không trang bị hệ thống an toàn

Từ hình 3 và bảng 2 cho thấy, đầu xe biến dạng thỏa mãn không gian an toàn, tuy nhiên hành khách và người lái va chạm vào phía sau ghế phía trước và vô lăng. Điều này cho thấy hành khách và người lái không sử dụng hệ thống ràng buộc (dây đai, túi khí) dẫn đến hành khách và người lái đều bị đa chấn thương. Hầu hết các chỉ số tổn thương của hành khách và người lái đều gấp nhiều lần so với tiêu chuẩn cho phép, đặc biệt là những chấn thương nghiêm trọng ở vùng đầu, cổ, và ngực. Chỉ số tổn thương đầu của hành khách số 1 và hành khách số 2 lên tới 15873 và 13029 , gấp $1587 \%$ và $1303 \%$ so với tiêu chuẩn cho phép, khiến cho cả 2 hành khách và người lái đều bị tổn thương nghiêm trọng, có thể gây ra thương vong. Do đó cần thiết phải trang bị hệ thống dây đai, túi khí nhằm bảo vệ, giảm tổn thương con người ngồi trong xe.

Bảng 2: Giá trị tổn thương ở trường hợp 1

\begin{tabular}{|l|l|l|l|l|l|}
\hline \multicolumn{2}{|c|}{ Chỉ số } & $\begin{array}{l}\text { Tiêu chuẩn } \\
\text { ECE R94 }\end{array}$ & Hành khách 1 & Hành khách 2 & Người lái \\
\hline \multirow{2}{*}{ Đầu } & HIC36 & 1000 & 15873 & 13029 & 5560 \\
\cline { 2 - 6 } & Gia tốc đầu $\left(\mathrm{m} / \mathrm{s}^{2}\right)$ & 80 & 382 & 367 & 208 \\
\hline \multirow{2}{*}{ Cổ } & $\begin{array}{l}\text { Momen uốn theo } \\
\text { phương y }(\mathrm{Nm})\end{array}$ & 57 & 209 & 185 & 131 \\
\hline \multirow{2}{*}{ Ngực } & Ép lồng ngực $(\mathrm{mm})$ & 50 & 21 & 30 & 73 \\
\cline { 2 - 7 } & $\begin{array}{l}\text { Vận tốc ép lồng ngực } \\
(\mathrm{m} / \mathrm{s})\end{array}$ & 1 & 0.59 & 0.56 & 1.30 \\
\hline
\end{tabular}

\subsection{Hành khách trang bị dây đai 2 điểm, người lái 3 điểm (trường họ̣p 2)}

Trường hợp này, hành khách được trang bị dây đai 2 điểm, người lái được trang bị dây đai 3 điểm, giống như trang bị thực tế trên xe khách ghế ngồi hiện nay. Kết quả mô phỏng và giá trị tổn thương của hành khách và tài xế được thể hiện ở hình 4 và bảng 3 . 


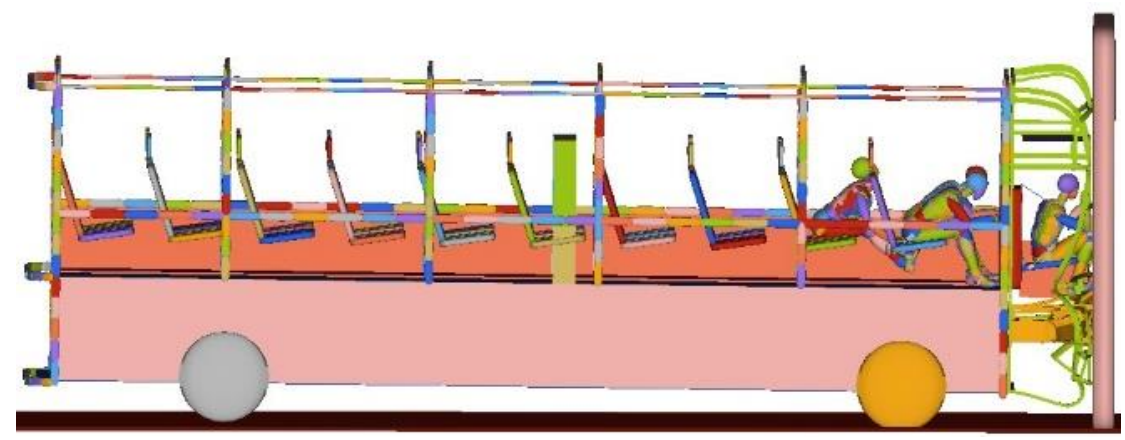

Hình 4: Hành khách trang bị dây đai 2 điểm, người lái 3 điểm

Bảng 3 cho thấy, đối với người lái được trang bị dây đai 3 điểm, các chỉ số tổn thương đều giảm xuống đáng kể, chỉ số tổn thương ngực thỏa mãn tiêu chuẩn, tuy nhiên chỉ số tổn thương đầu, cổ vẫn cao hơn so với tiêu chuẩn cho phép, nguy cơ tử vong còn ở mức cao. Với hành khách khi sử dụng dây đai 2 điểm, mặc dù các thông số tổn thương đã giảm đáng kể, tuy nhiên chỉ số tổn thương phần đầu, cổ, ngực vẫn vượt tiêu chuẩn, dẫn đến nguy cơ chấn thương vùng đầu, cổ nghiêm trọng.

Bảng 3: Giá trị tổn thương ở trường hợp 2

\begin{tabular}{|l|l|l|l|l|l|}
\hline \multicolumn{2}{|c|}{ Chỉ số } & Tiêu chuẩn ECE R94 & Hành khách 1 & Hành khách 2 & Người lái \\
\hline \multirow{2}{*}{ Đầu } & HIC36 & 1000 & 4145 & 6410 & 3881 \\
\cline { 2 - 6 } & Gia tốc đầu $\left(\mathrm{m} / \mathrm{s}^{2}\right)$ & 80 & 135 & 246 & 212 \\
\hline \multirow{2}{*}{ Cổ } & $\begin{array}{l}\text { Momen uốn theo phương } \\
\text { y (Nm) }\end{array}$ & 57 & 106 & 233 & 60 \\
\hline \multirow{2}{*}{ Ngực } & Ép lồng ngực $(\mathrm{mm})$ & 50 & 56.8 & 2.5 & 32.5 \\
\cline { 2 - 6 } & $\begin{array}{l}\text { Vận tốc ép lồng ngực } \\
(\mathrm{m} / \mathrm{s})\end{array}$ & 1 & 0.41 & 0.02 & 0.28 \\
\hline
\end{tabular}

\subsection{Hành khách trang bị dây đai 3 điểm, người lái 3 điểm và túi khí (trường họ̣p 3 )}

Kết quả mô phỏng trong trường hợp này được thể hiện ở hình 5 và bảng 4 . Từ bảng 4 cho thấy, giá trị tổn thương của hành khách và người lái giảm nhiều, phần đầu của hành khách thỏa mãn tiêu chuẩn, tuy nhiên giá trị mô men uốn cao hơn so với tiêu chuẩn; Đối với người lái, mặc dù trang bị dây đai, túi khí nhưng giá trị tổn thương đầu vẫn cao hơn tiêu chuẩn, gây nên tổn thương do cơ cấu an toàn chưa tối ưu hoặc là bộ phần đầu xe hấp thụ năng lượng va chạm chưa tốt. Để giảm tổn thương cho hành khách và người lái, ngoài việc trang bị hệ thống an toàn cần thiết kế cơ cấu hấp thụ năng lượng, giảm gia tốc va chạm.

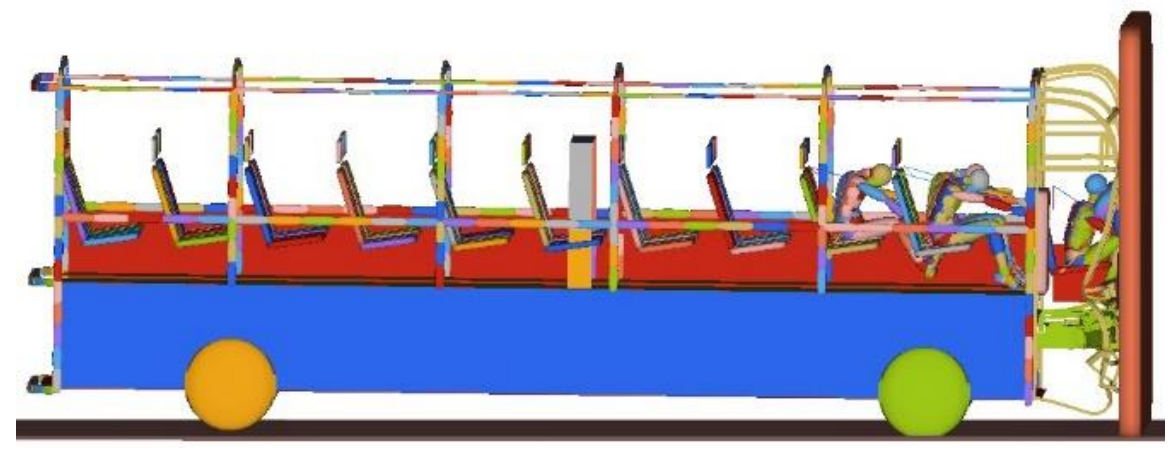

Hình 5: Hành khách trang bị dây đai 2 điểm, người lái 3 điểm 
Bảng 4: Giá trị tổn thương ở trường hợp 3

\begin{tabular}{|c|c|c|c|c|c|}
\hline \multicolumn{2}{|r|}{ Chỉ số } & Tiêu chuẩn ECE R94 & Hành khách 1 & Hành khách 2 & Người lái \\
\hline \multirow{2}{*}{ Đầu } & HIC36 & 1000 & 987 & 976 & 1335 \\
\hline & Gia tốc đầu $\left(\mathrm{m} / \mathrm{s}^{2}\right)$ & 80 & 79 & 81 & 92 \\
\hline Cổ & $\begin{array}{l}\text { Momen uốn theo } \\
\text { phương y }(\mathrm{Nm})\end{array}$ & 57 & 101 & 85 & 37 \\
\hline \multirow{2}{*}{ Ngực } & Ép lồng ngực (mm) & 50 & 55 & 53 & 33 \\
\hline & $\begin{array}{l}\text { Vận tốc ép lồng ngực } \\
(\mathrm{m} / \mathrm{s})\end{array}$ & 1 & 0.36 & 0.27 & 0.28 \\
\hline
\end{tabular}

\section{CẢI TIẾN TĂNG HẤP THỤ NĂNG LỰ̛̣NG, GIẢM TỔN THƯƠNG}

Nhằm tăng tính năng an toàn cho hành khách khi xe xảy ra va chạm trực diện, nghiên cứu này mô phỏng phân tích cơ chế tổn thương khi đầu xe trang bị cơ cấu hấp thu năng lượng va chạm, kết cấu cơ khí hấp thụ năng lượng được thể hiện ở hình 6 và hình 7 . Một cơ cấu hấp thụ năng lượng đặt trước đầu xe được thiết kế bao gồm các ống giảm chấn được biểu thị số 1 , thanh giảm chấn được biểu thị số 2 , cản trước giảm chấn được biểu thị số 3 . Kết cấu hấp thụ năng lượng sử dụng sắt $\mathrm{Q} 235$, thuộc tính vật liệu được thể hiện trong bảng 1 .
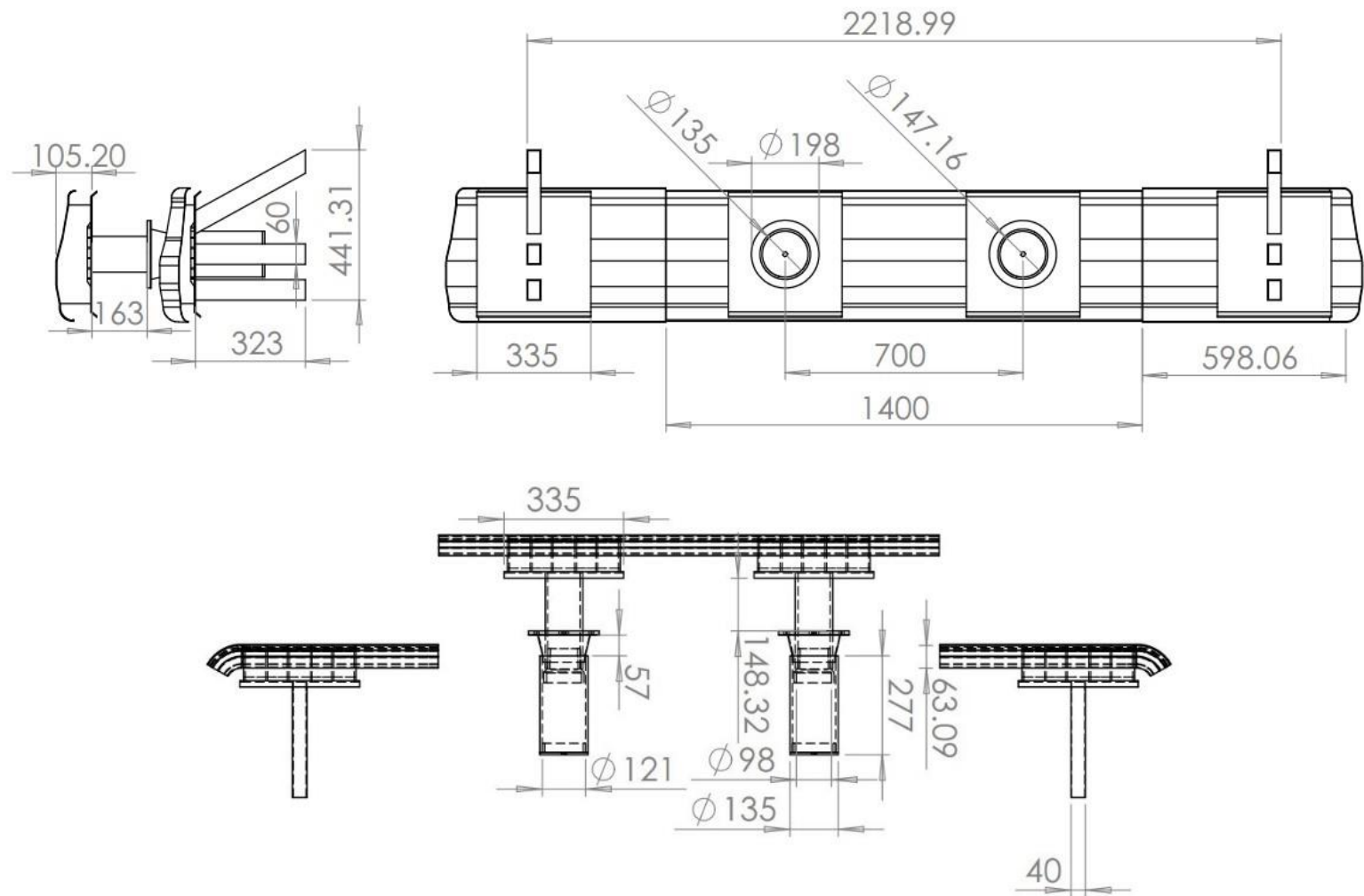

Hình 6: Cơ cấu CAD 2D bộ hấp thụ năng lượng

Bộ hấp thụ năng lượng đầy đủ được thể hiện ở hình 8 , khi xe không xảy ra va chạm thì cơ cấu được điều khiển lùi về phía trong đầu xe, hình dạng đầu xe lúc này giống như xe bình thường; khi xe có nguy cơ xảy ra va chạm thì hệ thống điều khiển bộ cản giảm chấn ở giữa tiến về phía trước thông qua hai ống giảm chấn số 1 . 


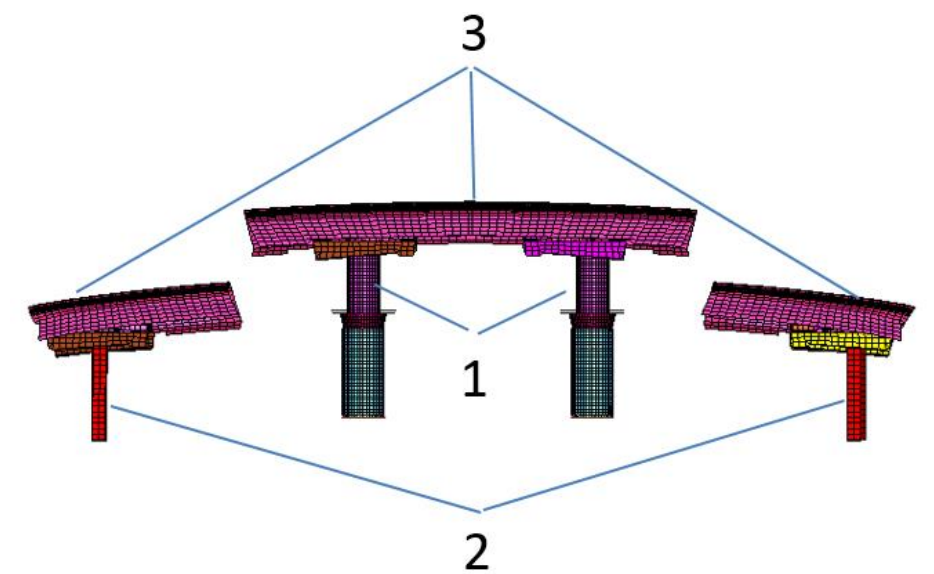

Hình 7: Cơ cấu phần tử hữu hạn bộ hấp thụ năng lượng

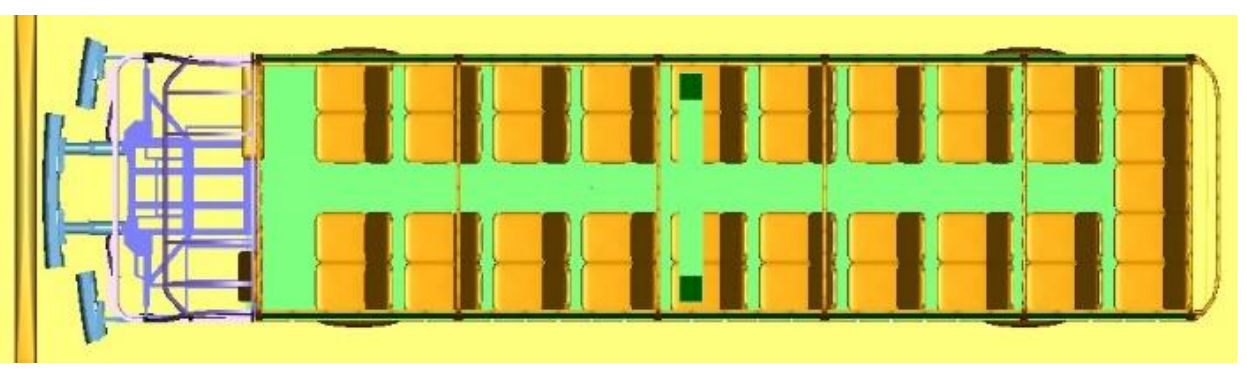

Hình 8: Cơ cấu hấp thụ năng lượng đặt ở đầu xe

Sau khi trang bị cơ cấu hấp thụ năng lượng va chạm tiến hành mô phỏng phân tích tổn thương hành khách và người lái cho 03 trường hợp có hay không trang bị hệ thống ràng buộc như ở phân tích trên. Kết quả mô phỏng được thể hiện ở hình 9 , hình 10 , hình 11 và bảng 5 .

Bảng 5 cho thấy, xét cho 3 trường hợp có và không trang bị hệ thống ràng buộc thì trường hợp 3 (hành khách trang bị dây đai 3 điểm, người lái sử dụng dây đai 3 điểm và túi khí) tất cả các giá trị tổn thương thỏa mãn tiêu chuẩn. Điều này cho thấy, khi cơ cấu hấp thụ năng lượng va chạm đặt trước đầu xe phát huy được tác dụng, tổn thương hành khách và tài xế giảm

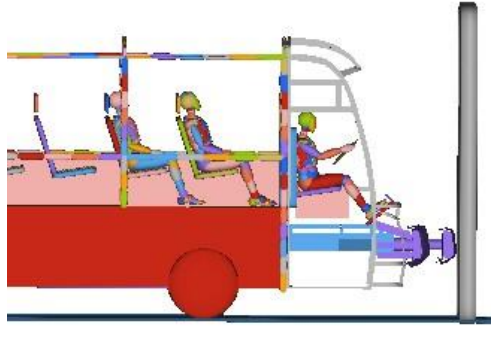

Trường hợp 1

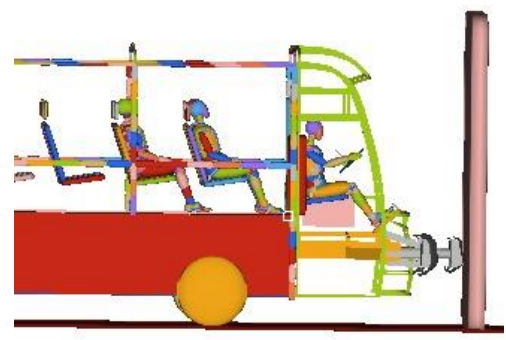

b) Trường hợp 2

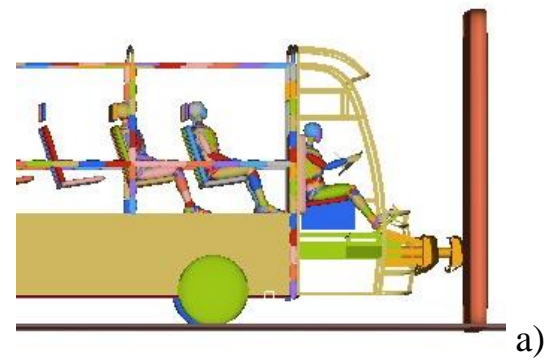

c) Trường hợp 3

Hình 9: Mô phỏng xe va chạm trực diện tại thời điểm 0 ms 


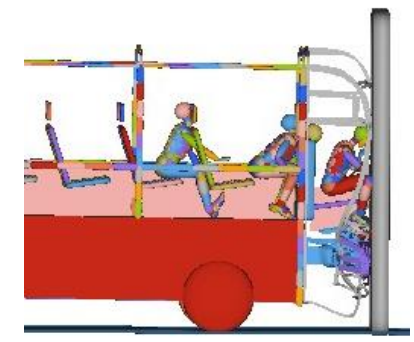

a) Trường hợp 1

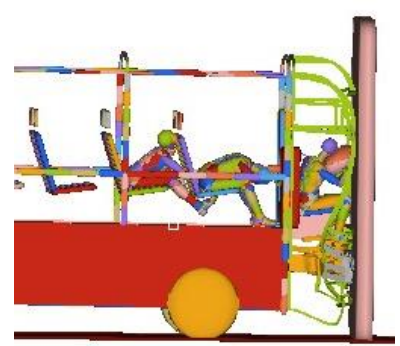

b) Trường hợp 2

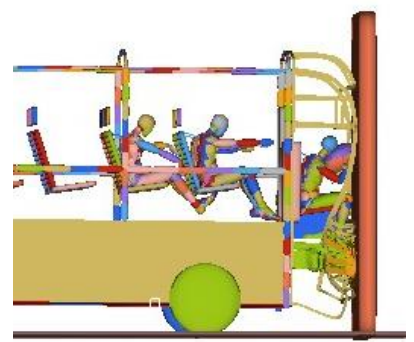

c) Trường hợp 3

Hình 10: Mô phỏng xe va chạm trực diện tại thời điểm 150 ms

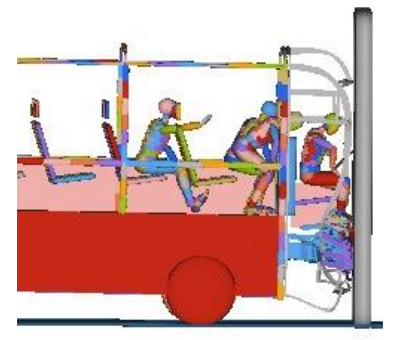

a) Trường hợp 1

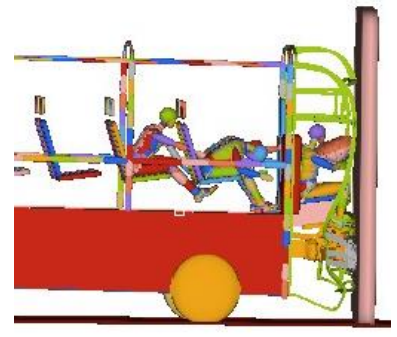

b) Trường hợp 2

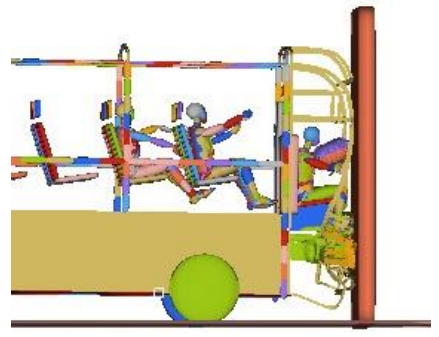

c) Trường hợp 3

Hình 11: Mô phỏng xe va chạm trực diện tại thời điểm 200 ms

Bảng 5: Giá trị tổn thương khi xe trang bị bộ phận hấp thụ năng lượng

\begin{tabular}{|c|c|c|c|c|c|c|c|c|c|c|c|}
\hline & \multirow[b]{2}{*}{ Chỉ số } & \multirow{2}{*}{$\begin{array}{l}\text { Tiêu } \\
\text { chuẩn }\end{array}$} & \multicolumn{3}{|c|}{ Trường hợp 1} & \multicolumn{3}{|c|}{ Trường hợp 2} & \multicolumn{3}{|c|}{ Trường hợp 3} \\
\hline & & & 1 & 2 & $\begin{array}{l}\text { Người } \\
\text { lái }\end{array}$ & 1 & 2 & $\begin{array}{l}\text { Người } \\
\text { lái }\end{array}$ & 1 & 2 & $\begin{array}{l}\text { Người } \\
\text { lái }\end{array}$ \\
\hline \multirow[b]{2}{*}{ Đầu } & HIC36 & 1000 & 10395 & 6161 & 3839 & 1834 & 5157 & 1084 & 230 & 278 & 154 \\
\hline & $\begin{array}{c}\text { Gia tốc } \\
\text { đầu }\left(\mathrm{m} / \mathrm{s}^{2}\right)\end{array}$ & 80 & 305 & 276 & 185 & 103 & 237 & 129 & 63 & 68 & 32 \\
\hline Cổ & $\begin{array}{c}\text { Momen } \\
\text { uốn theo } \\
\text { phương y } \\
(\mathrm{Nm})\end{array}$ & 57 & 122 & 92 & 78 & 42 & 56 & 15 & 23 & 22 & 24 \\
\hline \multirow[b]{2}{*}{ Ngực } & $\begin{array}{c}\text { Ép lồng } \\
\text { ngực (mm) }\end{array}$ & 50 & 2.5 & 2.4 & 76 & 31 & 2.4 & 26 & 33 & 33 & 28 \\
\hline & $\begin{array}{l}\text { Vần tốc ép } \\
\text { lồng ngực } \\
(\mathrm{m} / \mathrm{s})\end{array}$ & 1 & 0.07 & 0.15 & 1.07 & 0.13 & 0.02 & 0.10 & 0.13 & 0.08 & 0.17 \\
\hline
\end{tabular}

\section{KẾT LUẬN}

Nghiên cứu này dựa vào tiêu chuẩn an toàn Châu Âu ECE R94, ứng dụng phần mềm MADYMO, HYPERMESH đã tiến hành nghiên cứu an toàn tổn thương người ngồi trong xe khách khi xảy ra va chạm trực diện. Kết quả mô phỏng phân tích cho thấy, mặc dù hành khách và người lái có trang bị hệ thống an toàn nhưng giá trị tổn thương đầu, cổ, ngực lớn hơn giá trị tiêu chuẩn. Điều này cho thấy, kết cấu xe và kết cấu an toàn hấp thụ ít năng lượng va chạm. Để giảm tổn thương và an toàn cho con người ngồi trong xe cần thiết kế bộ hấp thụ năng lượng đặt trước đầu xe. Khi đó giá trị tổn thương đầu, cổ, ngực của hành khách và người lái trong trường hợp 3 thỏa mãn tiêu chuẩn ECE R94. 


\section{TÀI LIỆU THAM KHẢO}

[1] Minh Châm, 2015, 9 tháng đầu năm, hơn 16.000 vụ tai nạn giao thông trên cả nước. http://vovgiaothong.vn/duong-tin/9-thang-dau-namhon-16-000-vu-tai-nan-giao-thong-tren-ca-nuoc/134145

[2] Muhammad Aamir Hassan, Comparison of structural damage and occupant injuries corresponding to a vehicle collision onto a pole versus a flat barrier, Bachelor of Engineering, N.E.D. University of Engineering and technology Karachi, Pakistan, 2002.

[3] Nguyễn Thành Tâm, Thiết kế tối ưu hóa kết cấu khung xương và sát - xi ô tô khách. Khoa học Giáo dục Kỹ thuật, 31(2015): 29-35.

[4] Zhang Weigang, Simulation of bus safety body structure, Trường Đại Học Hồ Nam, Trung Quốc, 2006.

[5] Nguyễn Thành Tâm, Thiết kế cải tiến kết cấu xe ô tô khách thỏa mãn điều kiện an toàn va chạm trực diện. Phát triển khoa học \& công nghệ, 18(2015): 72-76.

Ngày nhận bài: 06/03/2017

Ngày chấp nhận đăng: 01/07/2017 